\section{Long shadow of Linnaeus's human taxonomy}

SIR - Your 15 March issue honouring Carl Linnaeus brings to mind what is probably his most significant contribution to modern life: the idea that groups of people can be regarded as naturally distinct taxonomic entities, or subspecies, in the same fashion as species, genera and higher categories.

In the first edition of Systema Naturae, published in 1735, before formalizing binominal species nomenclature, Linnaeus presented humans as sorting naturally into whitish Europeans (Homo Europaeus albescens), reddish Americans, dark Asians and blackish Africans. By the 10th edition, in 1758 , these had become subspecies, colour-coded as red Americans, white Europeans, yellow Asians and black Africans. In addition, Linnaeus separately listed wild children (Homo sapiens ferus) and a non-geographical grab-bag category, Homo sapiens monstrosus.

The idea that humans can be understood as constituting natural taxonomic units has bedevilled anthropology ever since. In the eighteenth century, both Johann Friedrich Blumenbach and Georges-Louis Leclerc, Comte de Buffon, recognized that the principal empirical patterns of human diversity are geographically gradual, which frustrates the project of human taxonomy. We would now say that pattern is 'clinal'.

Further, as anthropology matured, it clarified the fact that human groups principally differentiate themselves culturally - that is, by language, dress, principal deities, taboos and the like. The strongest antagonists are not the most biologically different, but simply the worst neighbours. Consequently, perceptions of group difference are local, political and ephemeral; but are nevertheless still commonly regarded as natural witness the racialization of categories such as 'Hispanic' and 'Middle Eastern' in the United States, and the newsworthy discovery in the United Kingdom that the Irish and the Scots are not so different after all ${ }^{2}$.

Genetics has been multivocal on the subject. On the one hand, it has emphasized the extensive polymorphism in the human gene pool $^{3}$, showing that there are all kinds of people everywhere - as fieldworkers had long known, but without quantitative support. On the other, it has focused on the small component of genetic variation that differs the most in the most widely separated peoples, and commonly interpreted the results in racial terms ${ }^{4}$.

It has taken two and a half centuries to shed Linnaeus's fallacy that the human species comes taxonomically organized into a few large, natural groups that are fairly homogeneous and fairly distinct from one another. We have come to understand, rather, that the predominant patterns of human variation are cultural, polymorphic, clinal and local.

This does not mean that everyone is the same, or that there is no biogeographic differentiation within our species. It means just that the effort to treat our own species taxonomically has considerably more social and symbolic than biological meaning. Jonathan Marks

Department of Sociology and Anthropology, University of North Carolina at Charlotte, Charlotte, North Carolina 28223, USA

1. Huxley, J. S. Nature 142, 219-220 (1938).

2. Oppenheimer, S. The Origins of the British: A Genetic Detective Story (Carroll \& Graf, 2006)

3. Lewontin, R. C. Evol. Biol. 6, 381-398 (1972)

4. Bamshad, M. J. et al. Am. J. Hum. Genet. 72, 578-589 (2003).

\section{Brain drain: gains all round when it goes both ways}

SIR - In your Editorial "In praise of the 'brain drain'” (Nature 446, 231; 2007), you ask how UK science flourishes despite the continual brain drain to California and elsewhere. One answer is the compensating in-drain from the Commonwealth, the rest of Europe and elsewhere.

Many universities in mainland Europe are dysfunctional in terms of the career ladder for young academics, influences in appointment, departmental management structure, research funding or senior management structure.

Two comments from people in my field: "I could never get an academic position in my country because my $\mathrm{PhD}$ supervisor is not good at academic politics"; and "In my [different] country, research funding is spread equally among all groups without regard to quality, and those doing outstanding work cannot get any more." Both these individuals have good positions in the United Kingdom and one was promoted rapidly to a personal chair at Cambridge University. There are many other examples.

Instead of complaining about the brain drain out, we should be encouraging the brain drain in. All $\mathrm{PhD}$ research studentships could be open equally to anyone in the world. Even those who then go back to their home country make a contribution in addition to the work they have done here: in a few years' time they start sending us their best output as $\mathrm{PhD}$ students or young postdocs, and the cycle repeats itself, with some of the new crop staying on.

I agree with your Editorial that the situation is good for the home countries, in the sense that there is a pool of people at the world forefront, available to be enticed back for senior appointments, and there is a pipeline for training the new students. If all the New Zealanders with good scientific jobs around the world tried to return to New Zealand, the country would burst! Volker Heine

Cavendish Laboratory, J. J. Thomson Avenue, Cambridge CB3 OHE, UK

\section{Brain drain: poor countries lose most and benefit least}

SIR - Your Editorial "In praise of the "brain drain'” (Nature 446, 231; 2007) is, in my opinion, misleading in its representation of the issue and in its attempt to justify phenomena that are debilitating for the education and training of professionals in the developing world.

The effects of these phenomena on countries differ, depending on the extent of a country's development. Developed countries, on the whole, have large numbers of scientists and healthcare and other professionals in their populations, whereas developing countries may have just a handful. A major obligation of any government to its population is to pursue and implement policies that increase numbers of these key professionals to a desirably stable level, or - where they are already approaching stability - to maintain them at those levels. This responsibility on governments is independent of international opinion and is the reason why South Africa may decide to penalize individuals who leave the country after having been trained at the state's expense, or rebuke companies that facilitate the mass emigration of its professionals.

The gains from money sent back home, or from some expatriates returning to their native countries much later in their careers, may be of some benefit to those countries. But it is difficult to imagine how this could be more useful than doctors, nurses, teachers or lecturers staying in places where such people are seriously lacking.

You mention the correlation of higher emigration rates with better public healthcare systems, but a correlation is not a causal link. What else would we expect when the countries that 'drain the brains' have the power to pick and choose? When migration occurs between countries that have no large disparity in their development levels, the exchange is more likely to be mutually beneficial.

Given all this, I believe that there is nothing to praise about the brain drain when it occurs en masse from the developing countries into richer, more developed ones with dramatically more power.

Andrew Isaac Meso

Royal Holloway University of London, Egham, Surrey TW20 OEX, UK

Contributions to Correspondence may be submitted to correspondence@nature.com. 